\title{
Long-term Outcomes of Kidney Transplantation in Fabry Disease
}

Sara Ersözlü, MD, ${ }^{1,2}$ Robert J. Desnick, MD, PhD, ${ }^{3}$ Uyen Huynh-Do, MD, ${ }^{4}$ Sima Canaan-Kühl, MD, ${ }^{5}$ Frédéric Barbey, MD, ${ }^{6}$ Vera Genitsch, MD, ${ }^{7}$ Thomas F. Mueller, MD, ${ }^{8}$ Marcus Cheetham, PhD, ${ }^{2}$ Andreas J. Flammer, MD, ${ }^{9}$ Stefan Schaub, MD, ${ }^{10}$ and Albina Nowak, MD ${ }^{2,9}$

Background. Fabry disease (FD) is a rare X-linked lysosomal storage disorder caused by mutations in the $\alpha$-galactosidase A gene that obliterate or markedly reduce a-galactosidase A activity. This results in the systemic accumulation of its glycosphingolipid substrates in body fluids and organs, including the kidney. Fabry nephropathy can lead to end-stage renal disease requiring kidney transplantation. Little is known about its long-term outcomes and the overall patient survival after kidney transplantation. Methods. Here, we report 17 Fabry patients (15 male and 2 female subjects) who received kidney transplants and their long-term treatment and follow-up at 4 specialized Fabry centers. Results. The posttransplant follow-up ranged to 25 years, with a median of 11.5 (range, 0.8-25.5] years. Graft survival was similar, and death-censored graft survival was superior to matched controls. Fabry patients died with functioning kidneys, mostly from cardiac causes. In 2 male subjects 14 and 23 years posttransplant, the grafts had a few typical FD lamellar inclusions, presumably originating from invading host macrophages and vascular endothelial cells. Conclusions. We conclude that kidney transplantation has an excellent long-term outcome in FD.

(Transplantation 2018;102: 1924-1933)

a abry disease (FD), a rare X-linked lysosomal storage disorder, is caused by mutations in the $\alpha$-galactosidase $\mathrm{A}$ gene $(G L A){ }^{1}$ The mutations result in markedly decreased or absent $\alpha$-galactosidase A ( $\alpha$-Gal A) enzymatic activity and the accumulation of its major substrate, globotriaosylceramide (Gb3), and its deacylated derivative, globotriaosylsphingosine $(\text { Lyso-Gb3 })^{2}$ in the fluids and cellular lysosomes throughout the body. Progressive Gb3 accumulation causes major organ damage, most frequently of the kidneys and heart. ${ }^{1}$

There are 2 major subtypes: the "classic" and "lateronset" phenotype. Classic male subjects have little or no residual $\alpha$-Gal A activity; have prominent vascular endothelial cell glycosphingolipid accumulation; and have childhood or

Received 20 November 2017. Revision received 17 March 2018.

Accepted 11 April 2018.

${ }^{1}$ Department of Cardiology, Inselspital, Bern University Hospital, Bern, Switzerland.

${ }^{2}$ Department of Internal Medicine, University Hospital Zurich, Zurich, Switzerland.

${ }^{3}$ Department of Genetics and Genomic Sciences, Icahn School of Medicine at Mount Sinai, New York, NY.

${ }^{4}$ Department of Nephrology and Hypertension, Inselspital, University of Bern, Bern, Switzerland.

5 Division of Nephrology and Intensive Care Medicine, CVK, Charité Universitätsmedizin, Berlin, Germany.

${ }^{6}$ Service of Genetic Medicine, University Hospital Lausanne, Switzerland.

${ }^{7}$ Institute of Pathology, University Bern, Bem, Switzerland.

${ }^{8}$ Department of Nephrology, University Hospital Zurich, Zurich, Switzerland.

${ }^{9}$ University Heart Centre, University Hospital Zurich, Zurich, Switzerland.

${ }^{10}$ Clinic for Transplantation Immunology and Nephrology, University Hospital Basel, Basel, Switzerland. adolescence onset of severe acroparesthesias, angiokeratoma, hypohidrosis, and corneal and lenticular opacities that, with age, progress to early demise primarily due to cardiac and renal involvement. ${ }^{3,4}$ Male subjects with the later-onset phenotype have residual $\alpha$-Gal A activity; have no vascular endothelial cell glycosphingolipid accumulation; lack the childhood/ adolescent hallmark symptoms; and predominantly experience progressive nephropathy, cardiomyopathy, and cerebrovascular disease in adulthood. ${ }^{5-7}$ Heterozygous female subjects also can be affected by the disease; however, their FD manifestations are variable and typically milder because of random X-chromosomal inactivation. 8,9

S.E. received a travel grant from Sanofi-Genzyme and Shire. A.N. received lecturing honoraria, and research support from Sanofi Genzyme and Shire and received financial publication support for this article from Sanofi Genzyme. R.J.D. is a consultant to Alexion Pharmaceuticals, Amicus Therapeutics, Sanofi-Genzyme, and Sangamo Therapeutics, has founder shares of Amicus Therapeutics and options of Sangamo Therapeutics, and receives royalties from Sanofi-Genzyme and Shire HRT. F.B. received a research grant from Shire. The other authors have no conflicts of interests.

S.E. and A.N. participated in the research design, performance of the research, data analysis, and writing of the paper. U.H.D., S.C.K., F.B., and S.S. participated in the performance of the research, data analysis, and writing of the paper. R.J.D. and V.G. participated in data analysis and the writing of the paper. T.N., A.F., and M.C. participated in writing of the paper.

Correspondence: Albina Nowak, M.D., University Heart Centre, University Hospital Zurich, Raemistrasse 100, 8091 Zurich, Switzerland. (albina.nowak@usz.ch).

Copyright (C) 2018 Wolters Kluwer Health, Inc. All rights reserved.

ISSN: 0041-1337/18/10211-1924

DOI: $10.1097 /$ TP.0000000000002252 
This means that Fabry nephropathy can lead to end-stage renal disease (ESRD) requiring dialysis or transplantation $(\mathrm{KTx})$ in male subjects and severely affected heterozygotes with both phenotypes. ${ }^{4,10,11}$ The first kidney transplant in an FD patient was conducted in 1967 in Basel, Switzerland. ${ }^{12}$ Initial reports advised against KTx in FD because of infectious and other complications and early transplant demise. ${ }^{13}$ Limited information is available about the long-term outcome of $\mathrm{KTx}$ in FD, particularly posttransplant survival. ${ }^{14-16}$ Later studies showed good survival rates, but mortality rates were high compared with non-Fabry recipients, mainly because of cardiovascular events. ${ }^{16}$ The longest previously reported graft survival was 10 years, ${ }^{14-18}$ and most patient outcome studies were conducted before the introduction of enzyme replacement therapy (ERT) ${ }^{14-17}$ or did not include data on the duration of and the number of patients undergoing ERT. ${ }^{15,16}$ Moreover, previous studies, most of which were registry analyses, did not report GLA mutations of recipients to confirm the FD diagnosis and determine the phenotypic subtype nor were systematic transplant biopsies performed. ${ }^{14-18}$ The impact of posttransplantation ERT was also unclear. Because the normal endogenous $\alpha$-Gal A activity in the graft should be sufficient for graft health, the recently reported European Best Practice Guideline on Fabry nephropathy recommended that ERT should be continued for nonrenal indications. ${ }^{19}$ Some early reports, particularly before the advent of ERT, found Gb3 deposits in kidney transplants, albeit in host macrophages or vascular endothelial cells that infiltrated the allograft. ${ }^{20-23}$ To further document the effects of renal transplants in FD, we conducted a long-term observational study that included follow-up of KTx grafts for up to 25 years in 17 Fabry patients, who were regularly treated and followed at 4 specialized FD centers.

\section{MATERIALS AND METHODS}

We investigated the FD patients that were transplanted and followed in Zurich, Bern, and Lausanne, Switzerland, and in Berlin, Germany. This study was conducted in accordance with the Declarations of Helsinki and Istanbul and approved by the respective center's ethics committee (KEK-ZH-Nr. 2014-0534, PB_2016-00360, and EKNZ 2015-403). All living patients provided written informed consent.

\section{Patient Selection, Characteristics, and Follow-up}

The databases of all participating centers were screened for patients with FD and kidney transplantation, and all identified patients were included in the study. The patients (15 male and 2 female subjects) were all regularly treated between 1979 and March 2017 at the 4 specialized FD centers in Zurich (patients 1-9), Bern (patients 10-12), Lausanne (patient 17), and Berlin (patients 13-16). The clinical data were extracted from medical records. Phenotyping was determined as reported previously. ${ }^{24}$ Separate annual follow-ups were carried out in the Fabry and transplant centers. ERT was initiated according to the written local guidelines. Accordingly, ERT was indicated in all male subjects, independent from age, phenotype, and symptoms. In heterozygotes, ERT was indicated if they had proteinuria of more than $300 \mathrm{mg}$ per day, Fabry-typical kidney biopsy findings, signs of Fabry cardiomyopathy such as left ventricular hypertrophy or arrhythmia, stroke or transient ischemic attack, persistent FD-related neuropathic pains despite conventional analgetic therapy, and/or gastrointestinal symptoms. ERT was prescribed at the licensed dose of either $0.2 \mathrm{mg} / \mathrm{kg}$ body weight of recombinant agalsidase-alpha (Replagal) or $1 \mathrm{mg} / \mathrm{kg}$ body weight agalsidase-beta (Fabrazyme) and given intravenously every 14 days.

\section{Endpoint Evaluation}

Cumulative patient and graft survival and death-censored graft survival were determined. Transplant function was regularly monitored at the respective FD and transplant centers. If a patient died outside the Fabry center, the date of death was obtained from the patient's general practitioner, family, or home care nurse administering ERT. All events were prospectively recorded and coded. The follow-up time was based on the date of the patient's death, graft loss, or the end of the study (March 31, 2017). Graft survival analysis was used to estimate the probability of a functioning graft at the study end. Graft failure was defined as graft loss or patient death, whichever came first. In addition, death-censored graft survival was used to estimate the probability of graft loss irrespective of death. For this purpose, the date of death in patients who died with a functioning graft was defined as the last follow-up. ${ }^{25}$

\section{Control Group and Matching Algorithm}

Data from non-FD KTx recipients were from the kidney transplant registry of the University Hospital Basel Switzerland and served as the control group. ${ }^{26}$ This registry contains detailed information on more than 2220 kidney transplant patients, grouped according to immunosuppression era, as previously published by Wehmeier et al., 2016, and classified as follows: first period 1967 to 1980 , second period 1981 to 1997, third period 1998 to 2004, and fourth period 2005 to 201 . $^{26}$

To compare graft survival and overall patient survival between FD and matched non-FD KTx controls, each FD recipient was best matched and blinded to the outcome in a 1:1 ratio. The matching algorithm is shown in Table 1 . The FD and non-FD KTx recipients were matched for sex, number of transplants, similar age with a maximum of $-2 /+4$ years, and KTx year \pm 3 years, similar number of human leukocyte

\section{TABLE 1.}

The matching algorithm of FD and non-FD recipients

\begin{tabular}{lc}
\hline Parameter & Deviation \\
\hline Sex & - \\
$\downarrow$ & \pm 3 years \\
Year of transplantation & \\
$\downarrow$ & $-2 /+4$ years \\
Age at transplantation & \\
$\downarrow$ & \\
Number of transplants & - \\
$\downarrow$ & \\
Presence of DSA & \\
$\downarrow$ & \\
HLA mismatches & \\
$\downarrow$ & \pm 1 \\
Immunosuppression era & \\
$\downarrow$ & max. 1 drug \\
Immunosuppression drugs &
\end{tabular}

DSA, donor-specific anti-HLA antibodies; HLA, human leukocyte antigen; max, maximum. 
antigen (HLA) mismatches \pm 2 , same status of donor-specific antigens (DSAs), belonged to the same immunosuppression period (when possible), and similar immunosuppression regime with a maximum of 1 drug difference (Table 2). A 1:1 matching ratio was preferred to $1: 2$ or $1: 3$ as it would have required further expansion of the matching criteria to find several matches for 1 patient.

\section{KTx Outcome and Gb3 Depositions}

The latest value of serum creatinine $(\mu \mathrm{mol} / \mathrm{L})$, estimated glomerular filtration rate (eGFR) calculated according to the Chronic Kidney Disease Epidemiology Collaboration (CKDEPI) equation, ${ }^{27}$ urinary protein/creatinine $(\mathrm{mg} / \mathrm{mmol})$, and albumin/creatinine $(\mathrm{mg} / \mathrm{mmol})$ ratios were used to assess KTx function. An eGFR below $15 \mathrm{~mL} / \mathrm{min}$ per $1.73 \mathrm{~m}^{2}$ was considered a transplant failure. Recurrence of Gb3 deposits in kidney transplants was assessed using electron microscopy
(EM) and/or histological analysis of kidney tissue from biopsies or autopsies.

\section{Statistical Analysis}

Continuous variables were expressed as medians with interquartile ranges. Kaplan-Meier analysis and log-rank test of survival distributions were calculated. The statistical analyses were performed using the SPSS/PC software package (version 23.0; SPSS Inc., Chicago, IL). All statistical tests were 2 sided, and $P<0.05$ were considered significant.

\section{RESULTS}

\section{Patients}

The patients' demographics, renal data, and KTx-related information are presented in Table 2 , and detailed clinical information, GLA genotypes, phenotypes, age at death, and

\section{TABLE 2.}

Demographics, donor type, baseline immunogenic risk, and clinical outcomes in FD recipients and matched non-FD controls

\begin{tabular}{|c|c|c|c|c|c|c|c|c|c|}
\hline Cause of ESRD & Sex & Age at KTx & Year of KTx & Donor type & $\begin{array}{l}\text { Number of HLA } \\
\text { mismatches }\end{array}$ & $\begin{array}{c}\text { Presence } \\
\text { of DSA }\end{array}$ & $\begin{array}{c}\text { Baseline } \\
\text { immunosuppression }\end{array}$ & Graft loss & Death \\
\hline $\mathrm{FD}(1)$ & $\mathrm{m}$ & 24 & 2005 & Living & 5 & No & $M, P, C$ & No & No \\
\hline Interstitial nephropathy & & 26 & 2002 & Living & 3 & & $M, P, C$ & No & No \\
\hline FD (2) & $\mathrm{m}$ & 40 & 1995 & Deceased & 3 & No & $A, P, C$ & No & Yes \\
\hline Extracapillary glomerulonephritis type II & & 41 & 1993 & Living & 3 & & $A, P, C$ & Yes & No \\
\hline FD (3) & $\mathrm{m}$ & 45 & 1993 & Deceased & 4 & No & $A, P, C$ & No & No \\
\hline Polycystic kidney disease & & 45 & 1994 & Living & 3 & & $A, P, C$ & No & No \\
\hline FD (4) & $\mathrm{m}$ & 61 & 2007 & Deceased & 4 & No & $M, P, C$ & No & No \\
\hline Hypertensive nephropathy & & 61 & 2007 & Deceased & 4 & & $M, P, T$ & No & No \\
\hline $\mathrm{FD}(5 \mathrm{a})^{\mathrm{a}}$ & $\mathrm{m}$ & 44 & 1999 & Deceased (first) & 3 & No & $M, P, C$ & Yes & Yes \\
\hline Diabetic nephropathy & & 46 & 1999 & Living (first) & 3 & & $M, P, C$ & Yes & No \\
\hline $\mathrm{FD}(5 \mathrm{~b})^{\mathrm{b}}$ & $\mathrm{m}$ & 56 & 2011 & Deceased (second) & 2 & Yes & $M, P, C$ & No & Yes \\
\hline Polycystic kidney disease & & 57 & 2010 & Deceased (second) & 3 & & $M, P, T$ & No & No \\
\hline $\mathrm{FD}(6)$ & M & 44 & 2011 & Deceased & 4 & No & $M, P, C$ & No & No \\
\hline Malignant nephrosclerosis & & 42 & 2010 & Deceased & 5 & & $M, P, T$ & Yes & No \\
\hline $\mathrm{FD}(7)$ & $\mathrm{m}$ & 17 & 1991 & Living & 2 & No & $A, P, C$ & Yes & No \\
\hline Chronic pyelonephritis & & 18 & 1990 & Living & 2 & & $A, P, C$ & Yes & No \\
\hline FD (8) & $\mathrm{m}$ & 35 & 1993 & Deceased & 4 & No & $P, C$ & No & Yes \\
\hline Chronic pyelonephritis due to VUR & & 34 & 1993 & Deceased & 3 & & $A, P, C$ & Yes & No \\
\hline FD (9) & $\mathrm{m}$ & 33 & 1979 & Deceased & 4 & No & $A, P$ & No & Yes \\
\hline Polycystic kidney disease & & 35 & 1977 & Deceased & 5 & & $A, P$ & Yes & No \\
\hline FD (10) & $\mathrm{m}$ & 28 & 1990 & Deceased & 3 & No & $A, P, C$ & No & Yes \\
\hline Chronic pyelonephritis due to VUR & & 28 & 1992 & Living & 2 & & $A, P, C$ & Yes & Yes \\
\hline $\mathrm{FD}(11)$ & $\mathrm{m}$ & 44 & 2014 & Living & 2 & No & $M, P, T$ & No & No \\
\hline Diabetic nephropathy & & 42 & 2014 & Living & 1 & & $M, P, T$ & No & No \\
\hline FD (12) & $\mathrm{m}$ & 27 & 1998 & Deceased & 3 & No & $M, P, C$ & No & No \\
\hline Chronic pyelonephritis & & 28 & 1997 & Living & 3 & & $M, P, C$ & Yes & No \\
\hline FD (13) & $\mathrm{m}$ & 53 & 2006 & Living & 3 & No & $M, P, C$ & No & No \\
\hline Hypertensive nephropathy & & 52 & 2004 & Living & 3 & & $M, P, C$ & No & No \\
\hline FD (14) & $f$ & 56 & 2016 & Living & 4 & No & $\mathrm{M}, \mathrm{P}, \mathrm{T}$ & No & No \\
\hline Polycystic kidney disease & & 57 & 2015 & Living & 5 & & $\mathrm{M}, \mathrm{P}, \mathrm{T}$ & No & No \\
\hline FD (15) & $\mathrm{m}$ & 16 & 2013 & Living & 3 & No & $\mathrm{M}, \mathrm{P}, \mathrm{T}$ & No & No \\
\hline Congenital anomalies of the kidney & & 20 & 2011 & Living & 3 & & $M, P, T$ & No & No \\
\hline FD (16) & $f$ & 45 & 2015 & Deceased & 0 & No & $\mathrm{M}, \mathrm{P}, \mathrm{T}$ & No & No \\
\hline Unknown & & 44 & 2015 & Deceased & 1 & & $\mathrm{M}, \mathrm{P}, \mathrm{T}$ & No & No \\
\hline FD (17) & $\mathrm{m}$ & 59 & 2002 & Deceased & 3 & No & $M, P, C$ & No & Yes \\
\hline Chronic glomerulonephritis & & 56 & 2002 & Deceased & 2 & & $M, P, C$ & Yes & Yes \\
\hline
\end{tabular}

${ }^{a}$ First and ${ }^{b}$ second transplant in the same FD recipient. A, azathioprine; C, cyclosporine; DSA, donor-specific anti-HLA antibodies; ESRD, end stage renal disease; FD, Fabry disease; f, female; HLA, human leukocyte antigen; KTx, kidney transplant; m, male; M, mycophenolate; P, prednisone; T, tacrolimus; VUR, vesicoureteral reflux. 


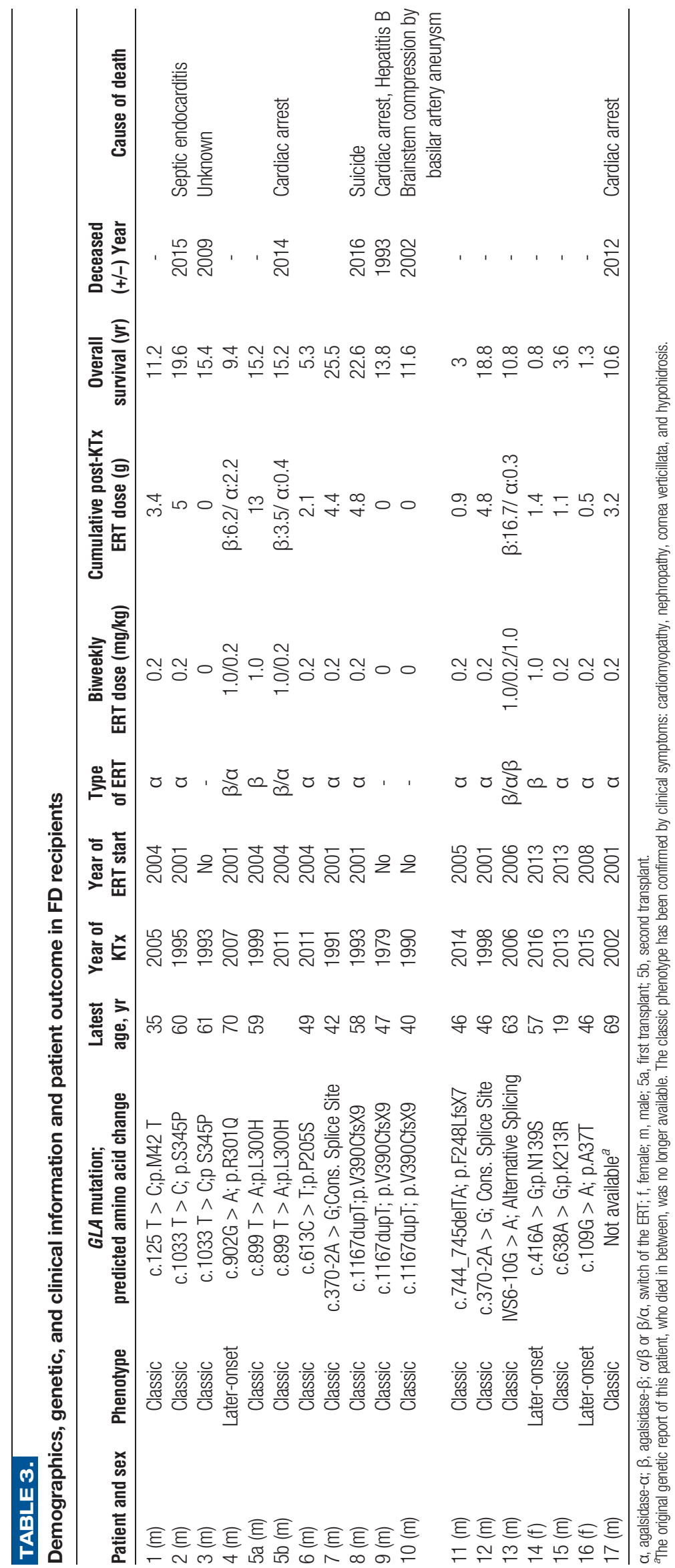


cause are presented in Tables 3 and 4 . There were 14 affected classic male subjects and 1 male subject with the later-onset phenotype who were diagnosed with FD at median ages of 34 (21-43) and 49 years, respectively. In addition, there were 2 severely affected heterozygotes, both from classically affected families, who were diagnosed at ages 38 and 54 years. The 15 male and 2 female patients were treated and followed for up to 25 years, with a median patient age of 53 (45-60) years as of March 31, 2017, or at death. In the majority, nephropathy was first diagnosed at ESRD, which then led to the diagnosis of FD. Diagnosis of nephropathy in the classically affected male subjects was made at the median age of 31 (21-43) years, in the later-onset male subject at 49 years, and at 25 and 42 years in the 2 heterozygotes. Chronic dialysis was initiated at a median age of 33 (22-43) years in the classically affected male subjects and at 38 years in 1 heterozygote and continued for a median time of $1(0.25-3.7)$ years before KTx was undertaken at the median age of 44 (28-47) years. Eleven patients received 12 kidneys from deceased and 6 patients from living donors. The living donors were 2 healthy fathers (both to male recipients), 1 mother (who was diagnosed with FD after donating the kidney to her undiagnosed son), 1 stepmother, and 2 spouses. Immunosuppression was prescribed according to local transplantation guidelines of the respective period. ${ }^{26}$ In this cohort, 5 patients were siblings belonging to 2 families with the classic phenotype. Recipients in family 1 included males 7 and 12 and family 2 included males 8, 9, and 10 .

\section{Enzyme Replacement Therapy}

Fourteen of the transplanted FD patients had ERT: 9 patients started before and continued after KTx (4 agalsidase- $\alpha$, 5 agalsidase- $\beta$ ) and 6 started after $\operatorname{KTx}(5$ agalsidase- $\alpha$, 1 agalsidase- $\beta$ ). Patient 5, who received 2 transplants, was counted in both categories. Their individual estimated cumulative agalsidase doses after KTx are indicated in Table 3. Patient 9 died in the pre-ERT era. Patient 10 died shortly after ERT became available. ERT was not provided to patient 3 because of the patient's frailty and dementia.

\section{Patient and Graft Survival}

During the median overall follow-up time of 11.5 years (range, 0.8-25.5), 11.6 years (7.6-17.1) for classic male subjects, 9.4 years for the later-onset male subject, and 0.8 and 1.3 years for the 2 heterozygotes. Seven classic male subjects died with functioning renal grafts (Table 3 ). The median age at death was 59 (47-61) years. Four of the 7 male deaths resulted from cardiac arrest secondary to hypertrophic cardiomyopathy and ventricular arrhythmias (in 2 cases, most likely triggered by septic endocarditis or hepatitis B), 1 died from a brain stem compression due to a large basilar artery aneurysm, 1 committed suicide, and 1 cause remains unknown (presumably cardiac due to known arrhythmias). The cumulative FD patient survival with $\mathrm{KTx}$ is shown in Figure 1. Cumulative graft survival in FD patients was similar to that of matched controls (Figure 2). Two kidney transplants were lost because of chronic transplant failure, (patients 5 and 7 after 9 and 22 years, respectively). Patient 5 was retransplanted at 9.1 years, and patient 7 was on the transplant waiting list at the end of this study. However, cumulative death-censored graft survival in FD patients was better than that of matched controls $(P=0.03$; Figure 3$)$. As noted previously, FD patients mainly died from cardiac events but with functioning grafts. Overall patient and graft survival is shown in Table 5. There were 10 patients who had functioning grafts 10 years postKTx that were all classic male subjects. Of the 10 patients who had functioning transplants at 10 years post-KTx, the median survival was $14.6(11.1-20.2)$ years.

\section{TABLE 4.}

Transplant-related information in the FD recipients

\begin{tabular}{|c|c|c|c|c|c|c|c|c|c|c|c|c|}
\hline \multirow{2}{*}{$\frac{\text { Patient }}{1}$} & \multirow{2}{*}{$\begin{array}{c}\begin{array}{c}\text { Age at } \\
\text { KTx, yr }\end{array} \\
24\end{array}$} & \multirow{2}{*}{$\begin{array}{c}\begin{array}{c}\text { Year } \\
\text { of KTx }\end{array} \\
2005\end{array}$} & \multirow{2}{*}{$\begin{array}{c}\begin{array}{c}\text { Survival } \\
\text { of } \mathbf{K T x}, \mathbf{y r}\end{array} \\
11.2\end{array}$} & \multicolumn{2}{|l|}{$\begin{array}{c}\text { Donor type and HLA } \\
\text { mismatches }\end{array}$} & \multicolumn{2}{|c|}{$\begin{array}{l}\text { Immunosuppression } \\
\text { at baseline at last }\end{array}$} & \multirow{2}{*}{$\begin{array}{c}\begin{array}{c}\text { eGFR } \\
\text { (mL/min) }^{a}\end{array} \\
60\end{array}$} & \multirow{2}{*}{ 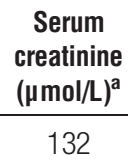 } & \multirow{2}{*}{$\begin{array}{c}\begin{array}{c}\text { Pro/C ratio } \\
\text { (mg/mmol) }^{\mathbf{a}}\end{array} \\
91\end{array}$} & \multirow{2}{*}{$\begin{array}{c}\begin{array}{c}\text { Alb/C ratio } \\
\text { (mg/mmol) }\end{array} \\
53.2\end{array}$} & \multirow{2}{*}{$\begin{array}{c}\begin{array}{c}\text { AT1-/ACE } \\
\text { inhibitors }\end{array} \\
0\end{array}$} \\
\hline & & & & Living (step mother) & 5 & $M, P, C$ & $\mathrm{M}, \mathrm{T}$ & & & & & \\
\hline 2 & 40 & 1995 & 19.6 & Deceased & 3 & $A, P, C$ & $M, C$ & 56 & 120 & 31 & $\mathrm{n} / \mathrm{a}$ & 0 \\
\hline 3 & 45 & 1993 & 15.4 & Deceased & 4 & $A, P, C$ & $A, C$ & 56 & 97 & 20 & $\mathrm{n} / \mathrm{a}$ & 1 \\
\hline 4 & 61 & 2007 & 9.4 & Deceased & 4 & $M, P, C$ & $M, C$ & 18 & 295 & 21 & 11.5 & 0 \\
\hline $5 a$ & 44 & 1999 & 9.1 & Deceased (first) & 3 & $M, P, C$ & $M, C$ & \multicolumn{4}{|c|}{ anuric } & 0 \\
\hline $5 b$ & 56 & 2011 & 3.2 & Deceased(second) & 2 & $M, P, C$ & $M, C$ & 42 & 154 & 22 & 9.3 & 0 \\
\hline 6 & 44 & 2011 & 5.3 & Deceased & 3 & $M, P, C$ & $M, C$ & 77 & 99 & no & 4.3 & 1 \\
\hline 7 & 17 & 1991 & 21.8 & Living (father) & 2 & $A, P, C$ & $P$ & \multicolumn{4}{|c|}{ anuric } & 1 \\
\hline 8 & 35 & 1993 & 22.6 & Deceased & 4 & $P, C$ & $P, C$ & 43 & 152 & 45 & 18.9 & 1 \\
\hline 9 & 33 & 1979 & 13.8 & Deceased & 1 & $A, P$ & $A, P$ & $\mathrm{n} / \mathrm{a}$ & $\mathrm{n} / \mathrm{a}$ & $\mathrm{n} / \mathrm{a}$ & $\mathrm{n} / \mathrm{a}$ & $\mathrm{n} / \mathrm{a}$ \\
\hline 10 & 28 & 1990 & 11.6 & Deceased & 3 & $A, P, C$ & $A, P, C$ & 27 & 282 & 109 & $\mathrm{n} / \mathrm{a}$ & 1 \\
\hline 11 & 44 & 2014 & 3 & Living (father) & 3 & $M, P, T$ & $\mathrm{M}, \mathrm{T}$ & 55 & 132 & 7 & 0.8 & 1 \\
\hline 12 & 27 & 1998 & 18.8 & Deceased & 2 & $\mathrm{M}, \mathrm{P}, \mathrm{C}$ & $\mathrm{M}, \mathrm{C}$ & 49 & 147 & 9 & 2.4 & 0 \\
\hline 13 & 53 & 2006 & 10.8 & Living (wife) & 3 & $M, P, C$ & $M, P, T$ & 63 & 101 & no & 0.4 & 1 \\
\hline 14 & 56 & 2016 & 0.8 & Living (husband) & 4 & $\mathrm{M}, \mathrm{P}, \mathrm{T}$ & $\mathrm{M}, \mathrm{P}, \mathrm{T}$ & 74 & 77 & 9.2 & 0.3 & 1 \\
\hline 15 & 16 & 2013 & 3.6 & Living (mother) & 3 & $M, P, T$ & $\mathrm{M}, \mathrm{T}$ & 98 & 96 & 9.8 & 0.8 & 1 \\
\hline 16 & 45 & 2015 & 1.3 & Deceased & 0 & $\mathrm{M}, \mathrm{P}, \mathrm{T}$ & $M, P, T$ & 49 & 115 & 7.8 & 0.2 & 0 \\
\hline 17 & 59 & 2002 & 10.6 & Deceased & 3 & $M, P, C$ & $M, C$ & 68 & 96 & 29 & 1.1 & 1 \\
\hline
\end{tabular}

${ }^{a}$ At the end of follow-up time or latest available results. A, azathioprine; Alb/C, albumin/creatinine; C, cyclosporine; M, mycophenolate; $\mathrm{P}$, prednisone; Pro/C, protein/creatinine; T, tacrolimus. 


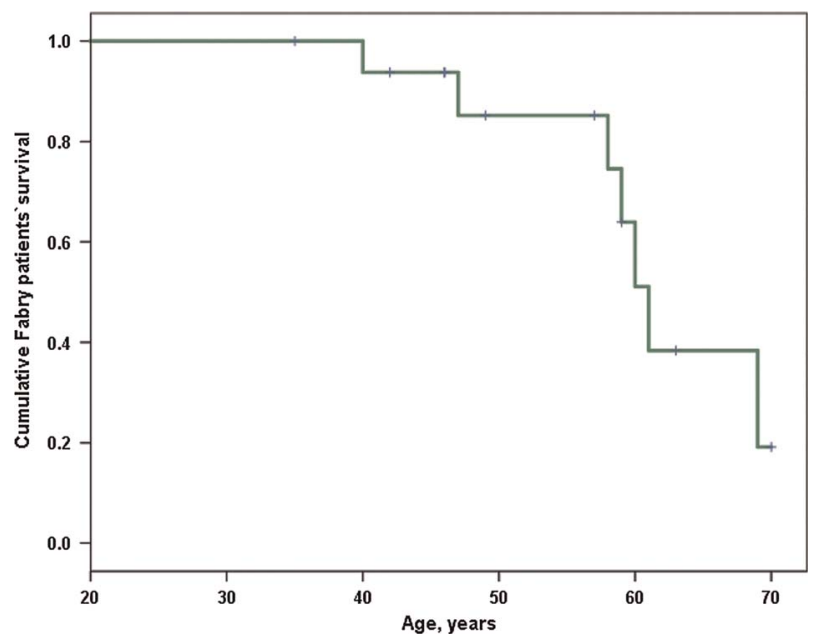

FIGURE 1. Cumulative survival of FD patients after KTx. Cumulative patient survival (Kaplan-Meier estimates) is shown for all FD patients after kidney transplantation $(n=17)$. The median age at the end of the study was 53 (45-60) years. Seven patients, all classic male subjects, died at a median age of 59 (47-61) years.

\section{Kidney Transplant Biopsies}

Twenty KTx biopsies were performed in 11 patients (Table 6). There were 4 patients with graft biopsies after at least 10 years (patients 7-10; biopsy after 11.6-22.6 years). There was no evidence of glycosphingolipid deposits in the transplanted kidneys with 2 exceptions among these patients (patients 8 and 9). A few electron-dense lamellar inclusions were identified in vascular endothelial cells in a classic male 14 years posttransplant (Figure 4 , patient 9). ${ }^{28}$ The invasion of vascular endothelial host cells into the graft endothelium can occur. ${ }^{23}$ This recipient was not on ERT as he died before it was available. The deceased donor of this recipient was a 35-year-old unrelated man. The other transplant recipient with ultrastructural deposits appearing as "zebra bodies" was the younger brother of the above patient (patient 8). He was transplanted 14 years before ERT was available;

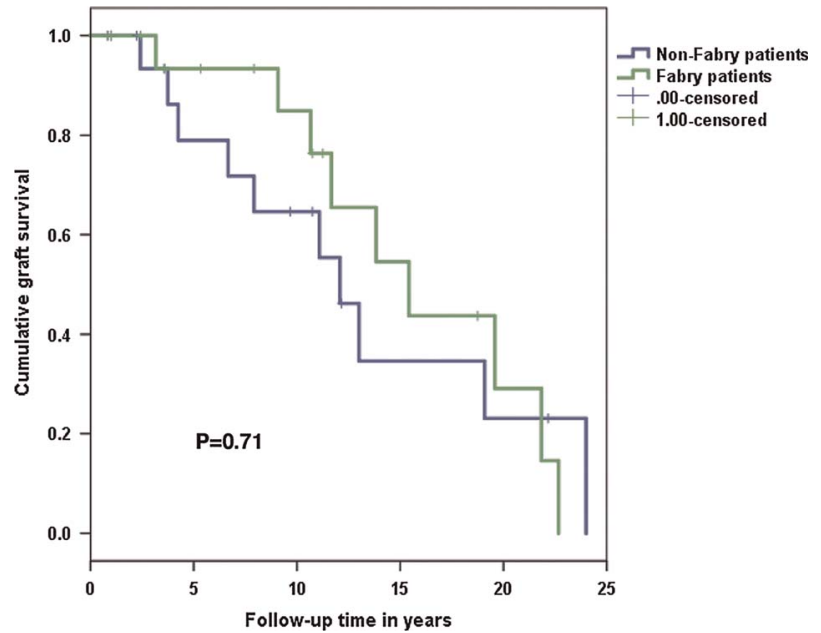

FIGURE 2. Cumulative graft survival in FD patients and matched controls. Cumulative graft survival is shown in FD patients and matched controls. Graft survival analysis was censored at graft loss or patient death, whichever came first. Graft survival is shown to be similar in FD patients and matched controls.

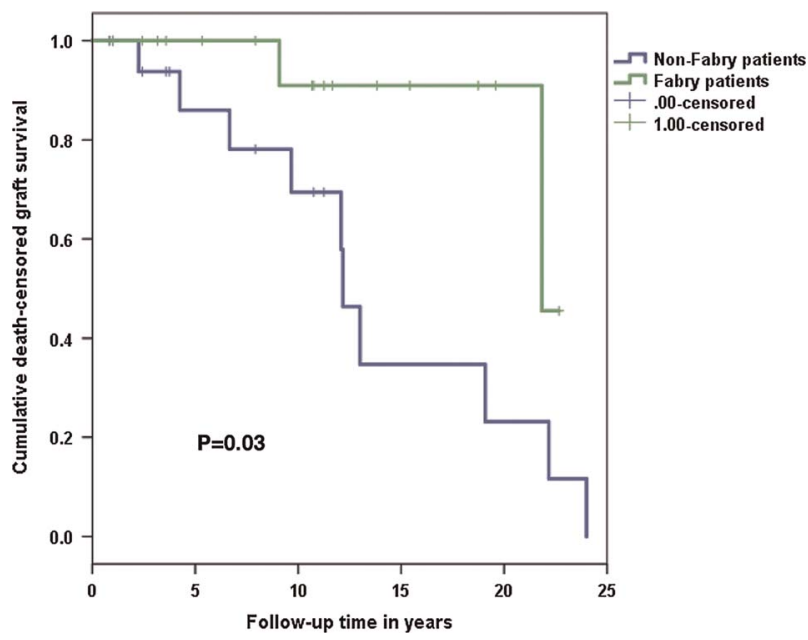

FIGURE 3. Death-censored graft survival in FD patients and matched controls. Cumulative death-censored graft survival is shown in FD patients and matched controls. Death-censored graft survival analysis is shown to be superior in Fabry patients, who mainly died with functioning kidneys, mostly from cardiac causes.

subsequently, he received ERT for 9 years, after which EM showed a few myelin figures, most likely originating from host histiocytes (Figure 5). In contrast, patient 7 (no ERT for 10 years, biopsy after 21.8 years) and patient 10 (no ERT at all, biopsy after 11.6 years) had no Gb3 deposits. Also in the other biopsies, no FD-specific changes were found on light and/or EM.

\section{DISCUSSION}

In this study, we found similar overall and superior deathcensored graft survival in the FD patients compared with non-FD matched controls. To our knowledge, these data describe the longest reported experience with $\mathrm{KTx}$ in $\mathrm{FD}$ - up to 25 years. All of the KTx recipients in our cohort who died were classic male subjects (median age at death, 59 years), who had functioning grafts, their deaths mainly due to cardiac events. Therefore, these findings highlight the importance of cardiovascular protection and ERT in this population. ERT should be beneficial in the long-term outcome of KTx patients, by treating the heart and clearing other host cells that can migrate into the graft including macrophages, histiocytes, and vascular endothelial cells. ${ }^{29}$ The recipients' survival rates were similar to non-FD recipients. Importantly, our high-risk population of predominantly classic male subjects, with most on ERT, survived longer (median age at death, 59 years) than reported for an FD male population without ERT (mean age at death, 49.9 years). ${ }^{3}$

TABLE 5.

Patient and graft survival at 5, 10, 15, 18, and 20 years

\begin{tabular}{lcccl}
\hline $\begin{array}{l}\text { Follow-up } \\
\text { time, yr }\end{array}$ & $\begin{array}{c}\text { Number } \\
\text { of patients }\end{array}$ & $\begin{array}{c}\text { Number } \\
\text { of grafts }\end{array}$ & Patient survival & Graft survival \\
\hline 5 & 13 & 14 & $100 \%(13 / 13)$ & $93 \%(13 / 14)$ \\
10 & 11 & 12 & $100 \%(11 / 11)$ & $92 \%(11 / 12)$ \\
15 & 9 & 10 & $67 \%(6 / 9)$ & $60 \%(6 / 10)$ \\
18 & 9 & 10 & $44 \%(4 / 9)$ & $40 \%(4 / 10)$ \\
20 & 8 & 9 & $25 \%(2 / 8)$ & $22 \%(2 / 9)$ \\
\hline
\end{tabular}




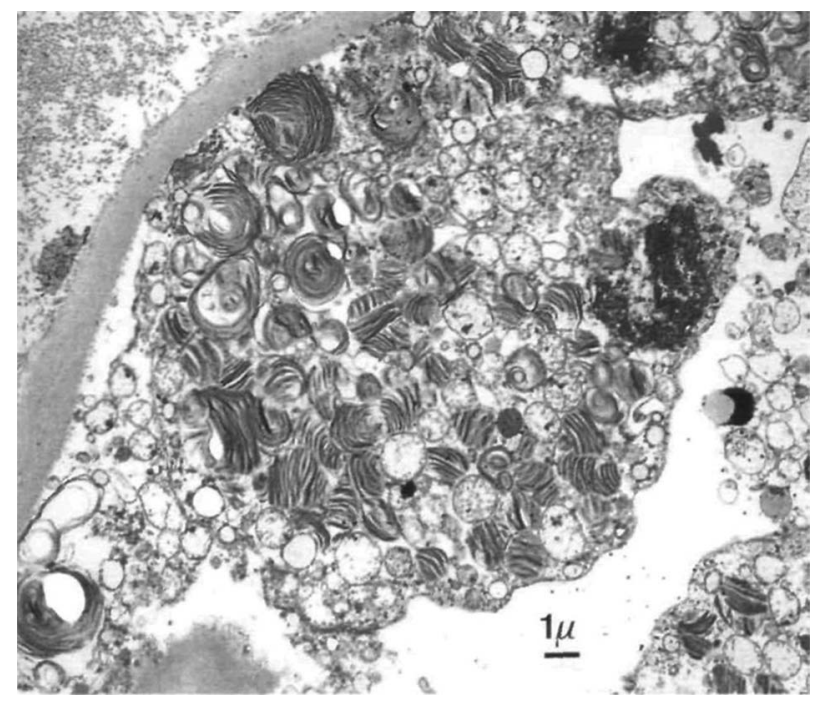

FIGURE 4. Electron microscopy of a kidney transplant 14 years without ERT. Formalin fixed and refixed in glutaraldehyde. Vascular endothelial cells showing numerous lamellar bodies in a patient with the mutation p.V390CfsX9. (EM x 3700, inset x 83 700). Previously published in Gantenbein et al., 1995 (Recurrence of Fabry's disease in a renal allograft 14 years after transplantation. Nephrol Dial Transplant. 1995;10(2):287-9), with permission. ${ }^{28}$

Several case reports of KTx in FD (Table 7) and a few registry studies ${ }^{14,16,18}$ have been published in the last 40 years, but all had shorter follow-up periods. With findings similar to ours, previous studies ${ }^{14-16}$ show patient and graft survival comparable to non-FD patients and found cardiac and cardiovascular events as major causes of mortality in FD patients. However, patient and graft survival rates in our patients were superior to the rates reported in studies from the pre-ERT era: the 10-year patient and graft survival in the present study exceeds $90 \%$, previous studies report $67 \%$ to $76 \%$ patient and $56 \%$ to $67 \%$ graft survival. ${ }^{14,15}$

KTx remains an important therapeutic option for Fabry nephropathy because ERT, when initiated late in the disease course, only slows progression. ${ }^{24,30,31}$ Germain et al. reported that patients who initiated treatment at older ages or had advanced renal disease or both experienced faster disease progression. ${ }^{32}$ The mean slope for eGFR for the 20 older patients (median age, 38 years) with urinary protein/creatinine ratio of greater than $0.5 \mathrm{~g} / \mathrm{g}$ or $50 \%$ or greater sclerotic glomeruli was $-6.82 \mathrm{~mL} / \mathrm{min}$ per $1.73 \mathrm{~m}^{2} / \mathrm{year}^{32}$ In contrast, the mean slope for eGFR for the 32 younger patients (median age, 25 years) with urinary protein/creatinine ratio of less than $0.5 \mathrm{~g} / \mathrm{g}$ or $50 \%$ or less sclerotic glomeruli was $-1.89 \mathrm{~mL} / \mathrm{min}$ per $1.73 \mathrm{~m}^{2} /$ year. In addition, the 3- to 5 -year survival rate of FD patients on chronic dialysis was less than that of the general dialysis population. ${ }^{33,34}$ Unfortunately, there are no comparative age-matched Fabry data for our sample from Switzerland and Germany that could serve as the denominator. The survival data of our transplanted Fabry patients can be compared with those of Fabry patients who underwent renal dialysis approximately 20 to 25 years ago. Thadhani et al. ${ }^{34}$ (2002) analyzed 137 FD patients in 2 cohorts, 1985 to 1993 (93 patients) and 1995 to 1998 (42 patients). Although not age matched, the overall 3-year survival rate for the 1985 to 1993 and 1995 to 1998 groups was $63 \%$ and $53 \%$, respectively. Tsakiris et al. ${ }^{33}$ (1996) reported that the 

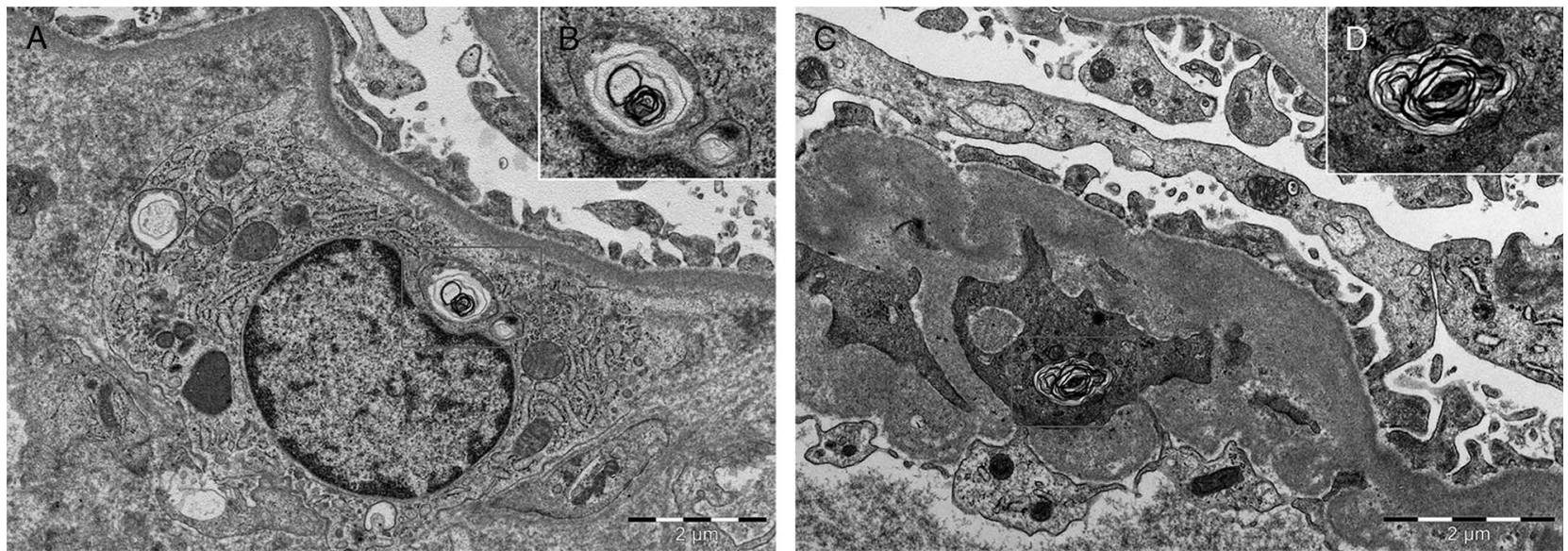

FIGURE 5. Electron microscopic findings of a kidney transplant biopsy in a recipient with FD 14 years without ERT. Single inclusions with lamellated structures - myeloid body —in a histiocyte, migrated into the graft vascular endothelium (A) (TEM, $\times 2800)$ and in a histiocyte, intercalated into a graft podocyte $(\mathrm{C})$. B and D, Higher magnification of the myeloid bodies showing the included storage material.

5 -year survival rate of 83 Fabry dialysis patients reported to the European Registry, who initiated dialysis from 1985 to 1993 , was only $41 \%$. Our findings that transplantation offers longer survival rates would support the recommendation that all transplantable patients with suitable donors (living-related or histocompatible) should be transplanted when possible.

In our cohort, only 2 grafts in classic male brothers had renal lysosomal substrate inclusions on EM. Lamellar lysosomal inclusions were present in vascular endothelial cells of the older brother 13.8 years post-KTx (pre-ERT era), presumably because of the endothelial cell invasion from the host into the graft. ${ }^{23}$ In his younger transplanted brother who began ERT 14.3 years posttransplant and was biopsied 22.7 years after KTx, biopsy showed isolated inclusions in histiocytes, which also migrated into the transplant from the host. In contrast to these patients, 2 other patients, who were also not under ERT for a long time (10 and 11.6 years) and were biopsied after 11.6 and 21.8 years had no lysosomal inclusions by light and EM.
An important differential diagnosis in the interpretation of the myelin figures and zebra bodies found in renal biopsies are drug-induced phenocopies of $\mathrm{FD}^{1}$ - ultrastructural changes that appear morphologically similar to those due to FD. ${ }^{40-43}$ Certain cationic amphiphilic drugs and their derivates are inhibitors of $\alpha-\mathrm{Gal} A$ and can cause renal inclusions which appear similar to FD inclusions and are reversible after discontinuation $^{40}$ : (hydro)-chloroquine $\mathrm{e}^{43-45}$ and amiodarone $\mathrm{e}^{46,47}$ are direct inhibitors of $\alpha$-Gal A, and gentamicin ${ }^{40}$ ranolazine, ${ }^{48}$ pentamidine, ${ }^{49}$ and macrolide ${ }^{50}$ also cause the phenotype. Silicosis results in inclusions that mimic those in FD, and thus, similar observations were made in silica-induced nephropathy. ${ }^{1,51}$

Early studies reported increased levels of plasma $\alpha-G a l$ A activity post-KTx ${ }^{20,52}$ which were later shown to be due to increased $\alpha-\mathrm{N}$-acetylgalactosaminidase ( $\alpha$-Gal B) activity, an enzyme evolutionarily related to $\alpha-\mathrm{Gal} \mathrm{A},{ }^{53,54}$ that is assayed using the same fluorogenic substrate. Thus, the increased $\alpha$-Gal A activity was an artifact. Subsequently, one of the authors (R.J.D.) showed that plasma $\alpha-G a l$ B activity was increased because of the immunosuppression medications (R.J.D., unpublished data, 1973).

\section{TABLE 7}

Case reports of kidney biopsies from the pre-ERT era

\begin{tabular}{|c|c|c|c|}
\hline Year of publication & Authors & Time point of microscopy & Histological findings \\
\hline 1972 & Clarke et al. ${ }^{20}$ & 7 months (autopsy) & EM: intracellular multilamellar bodies, epithelium was normal; no accumulation of glycolipids \\
\hline 1973 & Bühler et al. $^{12}$ & 17 months (autopsy) & $\overline{\text { No }}$ deposits \\
\hline 1981 & Faraggiana et al. $^{21}$ & 6 months & $\begin{array}{l}\text { LM: glomerular, tubular and interstitial deposits } \\
\text { EM: few inclusions on the vascular endothelium }\end{array}$ \\
\hline 1982 & Clement et al. ${ }^{35}$ & 15 months (autopsy) & LM and EM: normal \\
\hline 1982 & Bannwart et al. ${ }^{36}$ & 12 yrs & 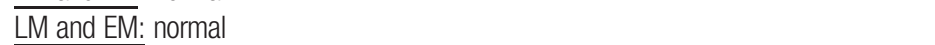 \\
\hline 1986 & McMahon et al. ${ }^{23}$ & 4 yrs & $\overline{\text { Accumulation in endothelial cells leading to narrowing and occlusions }}$ \\
\hline 1987 & Friedlaender et al. $^{22}$ & 8 yrs & $\begin{array}{l}\text { LM: no abnormalities } \\
\underline{\text { EM: }} \text { occasional small myelin figures in the vascular endothelium }\end{array}$ \\
\hline 1987 & Popli et al. ${ }^{37}$ & $5.5 \mathrm{yrs}$ & $\begin{array}{l}\text { donor was heterozygous sister } \\
\text { LM and EM: FD typical changes }\end{array}$ \\
\hline 1991 & Mosnier et al. ${ }^{38}$ & 11 yrs (autopsy) & $\begin{array}{l}\text { LM: normal } \\
\text { EM: sphingolipid inclusions in the vascular endothelium }\end{array}$ \\
\hline 1995 & Gantenbein et al. ${ }^{28}$ & 14 yrs (autopsy) & $\begin{array}{l}\mathrm{LM}: \text { no abnormalities } \\
\mathrm{EM}: \text { massive tubular, interstitial and endothelial deposits of Gb3 }\end{array}$ \\
\hline 1998 & Erten et al. ${ }^{39}$ & $10 \mathrm{yrs}$ & LM and EM: normal \\
\hline
\end{tabular}

EM, electron microscopy; FD, Fabry disease; LM, light microscopy. 
Importantly, FD does not recur in kidney transplants, in contrast to other renal diseases. ${ }^{55}$ Among hereditary systemic diseases, primary hyperoxaluria type 1 or adenine phosphoribosyl transferase deficiency have high recurrence rates of renal disease in the transplant. ${ }^{55,56}$ In cystinosis, cysteine-laden cells were occasionally observed in the grafts but were found to be without clinical relevance. ${ }^{55}$ In Alport syndrome, antiglomerular basement membrane antibodies were occasionally found. ${ }^{55}$ Primary renal diseases that recur in the transplant include membranoproliferative glomerulonephritis (approximately $30 \%$ in type $1,80 \%$ in type 2$),{ }^{55}$ focal segmental glomerulosclerosis $(30 \%-50 \%),{ }^{57}$ and IgA nephropathy $(50 \%) .{ }^{55}$ This is not the experience in FD: if the graft is healthy, it can function well for at least 25 years as documented here.

Specific challenges of KTx in FD should be noted. Recipients or donors might have undiagnosed FD because FD is not part of the routine pretransplant workups. ${ }^{58}$ Individuals with unrecognized FD may donate their kidneys to non-Fabry patients (e.g., ${ }^{58}$ ), which can lead to early graft dysfunction and chronic kidney disease in the living donor and recipient. ${ }^{33}$ Living kidney donations can occur within families with unrecognized FD relatives. ${ }^{37,59}$ Thus, it is important to perform genetic testing for FD where there is clinical suspicion of FD or an unclear nephropathy.

A limitation of this report is the size of the patient sample. This is an inherent limitation in rare diseases. Moreover, we might be analyzing survivor advantage, as Fabry patients may not reach transplantation, especially in the era of late diagnosis. Furthermore, we have no way to determine, if all Fabry patients were diagnosed pretransplant. There could have been unrecognized Fabry patients with kidney transplantation in whom the diagnosis of FD was not made. However, and in contrast to previous KTx reports, ${ }^{14,16,18}$ most patients had a graft biopsy, and the majority had biopsy or autopsy EM to exclude Gb3 deposits in the graft. EM was not conducted in some of the donor kidneys because the deposits were generally considered unlikely in a non-FD kidney. On the other hand, light microscopy can identify FD-related kidney changes. ${ }^{11}$ The strengths of the study are that it was a multicenter design, had no dropouts to follow-up, and applied regular multidisciplinary patient assessments; the study also included the complete collection of clinical, biochemical, genetic, and phenotypic information; data on the immunogenic pretransplantation risk; and regular and serial KTx biopsies. These advantages were frequently lacking in other studies. Importantly, this study used a well-matched non-FD control group that was also exposed to the same environmental conditions because of medical treatment and geographic and cultural proximities of the FD and non-FD recipients. As Fabry patients requiring transplantation are generally younger than the overall transplant patient population and, on that basis, might be expected to have better outcomes, we have used an age-matched control group to avoid this potential bias. Because it is not sufficient to match age and sex to reach an equal start line, we also matched according to the immunosuppression era, number of transplants, and presence of DSA and HLA mismatches.

\section{CONCLUSIONS}

In conclusion, the study shows similar graft survival and superior death-censored graft survival in FD patients compared with non-FD matched controls. ERT may improve patient survival and protect kidney grafts from invasion of host cells containing Gb3 deposits. Finally, the study data further support KTx in FD only using a screened-negative donor for FD.

\section{ACKNOWLEDGMENT}

Figure 5 was originally published in Gantenbein et al. 1995 (Recurrence of Fabry's disease in a renal allograft 14 years after transplantation, Nephrol Dial Transplant, 1995 Volume 10 pages $287-289$ ) by permission of Oxford University Press.

\section{REFERENCES}

1. Desnick R, loannou Y, Eng C. a-Galactosidase A deficiency: Fabry disease. In: Scriver CR, Beaudet AL, Sly WS, et al., editors. The Metabolic and Molecular Bases of Inherited Disease. New York: McGraw-Hill; 2001: 3733-3774.

2. Aerts JM, Groener JE, Kuiper S, et al. Elevated globotriaosylsphingosine is a hallmark of Fabry disease. Proc Natl Acad Sci U S A. 2008;105: 2812-2817.

3. Schiffmann R, Warnock DG, Banikazemi M, et al. Fabry disease: progression of nephropathy, and prevalence of cardiac and cerebrovascular events before enzyme replacement therapy. Nephrol Dial Transplant. 2009;24:2102-2111

4. Desnick RJ, Brady R, Barranger J, et al. Fabry disease, an underrecognized multisystemic disorder: expert recommendations for diagnosis, management, and enzyme replacement therapy. Ann Intern Med. 2003;138:338-346.

5. von Scheidt W, Eng CM, Fitzmaurice TF, et al. An atypical variant of Fabry's disease with manifestations confined to the myocardium. N Engl J Med. 1991;324:395-399.

6. Nakao S, Kodama C, Takenaka T, et al. Fabry disease: detection of undiagnosed hemodialysis patients and identification of a "renal variant" phenotype. Kidney Int. 2003;64:801-807.

7. Shabbeer J, Yasuda M, Benson SD, et al. Fabry disease: identification of 50 novel alpha-galactosidase A mutations causing the classic phenotype and three-dimensional structural analysis of 29 missense mutations. Hum Genomics. 2006;2:297-309.

8. Linthorst GE, Poorthuis BJ, Hollak CE. Enzyme activity for determination of presence of Fabry disease in women results in $40 \%$ false-negative results. J Am Coll Cardiol. 2008;51:2082; author reply 2082-2083.

9. Echevarria L, Benistan K, Toussaint A, et al. X-chromosome inactivation in female patients with Fabry disease. Clin Genet. 2016;89:44-54.

10. Branton M, Schiffmann R, Kopp JB. Natural history and treatment of renal involvement in Fabry disease. J Am Soc Nephrol. 2002;13(Suppl 2): S139-S143.

11. Alroy J, Sabnis S, Kopp JB. Renal pathology in Fabry disease. J Am Soc Nephrol. 2002;13(Suppl 2):S134-S138.

12. Bühler FR, Thiel G, Dubach UC, et al. Kidney transplantation in Fabry's disease. Br Med J. 1973;3:28-29.

13. Maizel SE, Simmons RL, Kjellstrand C, et al. Ten-year experience in renal transplantation for Fabry's disease. Transplant Proc. 1981;13(1 Pt 1): 57-59.

14. Ojo A, Meier-Kriesche HU, Friedman G, et al. Excellent outcome of renal transplantation in patients with Fabry's disease. Transplantation. 2000; 69:2337-2339.

15. Inderbitzin D, Avital I, Largiader F, et al. Kidney transplantation improves survival and is indicated in Fabry's disease. Transplant Proc. 2005;37: 4211-4214.

16. Shah T, Gill J, Malhotra N, et al. Kidney transplant outcomes in patients with Fabry disease. Transplantation. 2009;87:280-285.

17. Obrador GT, Ojo A, Thadhani R. End-stage renal disease in patients with Fabry disease. J Am Soc Nephrol. 2002;13(Suppl 2):S144-S146.

18. Cybulla M, Walter KN, Schwarting A, et al. Kidney transplantation in patients with Fabry disease. Transpl Int. 2009;22:475-481.

19. Terryn W, Cochat P, Froissart R, et al. Fabry nephropathy: indications for screening and guidance for diagnosis and treatment by the European Renal Best Practice. Nephrol Dial Transplant. 2013;28:505-517.

20. Clarke JT, Guttmann RD, Wolfe LS, et al. Enzyme replacement therapy by renal allotransplantation in Fabry's disease. N Engl J Med. 1972;287: 1215-1218.

21. Faraggiana T, Churg J, Grishman E, et al. Light- and electron-microscopic histochemistry of Fabry's disease. Am J Pathol. 1981;103:247-262. 
22. Friedlaender MM, Kopolovic J, Rubinger D, et al. Renal biopsy in Fabry's disease eight years after successful renal transplantation. Clin Nephrol. 1987;27:206-211.

23. McMahon J, Tubbs R, Gephardt G, Steinmuller D. Pseudo-Reoccurence of Fabry's Disease in renal allograft. Paper presented at: LABORATORY INVESTIGATION. 1986.

24. Nowak A, Koch G, Huynh-Do U, et al. Disease progression modeling to evaluate the effects of enzyme replacement therapy on kidney function in adult patients with the classic phenotype of Fabry disease. Kidney Blood Press Res. 2017;42:1-15.

25. EBPG Expert Group on Renal Transplantation. European best practice guidelines for renal transplantation. Section IV: Long-term management of the transplant recipient. IV.13 Analysis of patient and graft survival. Nephrol Dial Transplant. 2002;17(Suppl 4):60-67.

26. Wehmeier C, Georgalis A, Hirt-Minkowski P, et al. 2222 kidney transplantations at the University Hospital Basel: a story of success and new challenges. Swiss Med Wkly. 2016;146:w14317.

27. Levey AS, Stevens LA, Schmid CH, et al. A new equation to estimate glomerular filtration rate. Ann Intern Med. 2009;150:604-612.

28. Gantenbein H, Bruder E, Burger HR, et al. Recurrence of Fabry's disease in a renal allograft 14 years after transplantation. Nephrol Dial Transplant. 1995; 10:287-289.

29. Eng CM, Guffon N, Wilcox WR, et al. Safety and efficacy of recombinant human alpha-galactosidase A-replacement therapy in Fabry's disease. N Engl J Med. 2001;345:9-16.

30. Weidemann F, Niemann M, Stork S, et al. Long-term outcome of enzymereplacement therapy in advanced Fabry disease: evidence for disease progression towards serious complications. J Intern Med. 2013;274:331-341.

31. Banikazemi M, Bultas J, Waldek S, et al. Agalsidase-beta therapy for advanced Fabry disease: a randomized trial. Ann Intern Med. 2007;146:77-86.

32. Germain DP, Charrow J, Desnick RJ, et al. Ten-year outcome of enzyme replacement therapy with agalsidase beta in patients with Fabry disease. J Med Genet. 2015;52:353-358.

33. Tsakiris D, Simpson HK, Jones EH, et al. Report on management of renale failure in Europe, XXVI, 1995. Rare diseases in renal replacement therapy in the ERA-EDTA Registry. Nephrol Dial Transplant. 1996;11(Suppl 7):4-20.

34. Thadhani R, Wolf M, West ML, et al. Patients with Fabry disease on dialysis in the United States. Kidney Int. 2002;61:249-255.

35. Clement M, McGonigle RJ, Monkhouse PM, et al. Renal transplantation in Anderson-Fabry disease. J R Soc Med. 1982;75:557-560.

36. Bannwart F. Fabry's disease. Light and electron microscopic cardiac findings 12 years after successful kidney transplantation. Schweiz Med Wochenschr. 1982;112:1742-1747.

37. Popli S, Molnar ZV, Leehey DJ, et al. Involvement of renal allograft by Fabry's disease. Am J Nephrol. 1987;7:316-318.

38. Mosnier JF, Degott C, Bedrossian J, et al. Recurrence of Fabry's disease in a renal allograft eleven years after successful renal transplantation. Transplantation. 1991;51:759-762.

39. Erten Y, Ozdemir FN, Demirhan B, et al. A case of Fabry's disease with normal kidney function at 10 years after successful renal transplantation. Transplant Proc. 1998;30:842-843.

40. Reasor MJ, Kacew S. Drug-induced phospholipidosis: are there functional consequences? Exp Biol Med (Maywood). 2001;226:825-830.
41. Sakuraba H, Tsukimura T, Tanaka T, et al. Clinical and biochemical investigation of male patients exhibiting membranous cytoplasmic bodies in biopsied kidney tissues; a pitfall in diagnosis of Fabry disease. J Nephropathol. 2015;4:91-96

42. Bracamonte ER, Kowalewska J, Starr J, et al. Iatrogenic phospholipidosis mimicking Fabry disease. Am J Kidney Dis. 2006;48:844-850.

43. de Menezes Neves PDM, Machado JR, Custodio FB, et al. Ultrastructural deposits appearing as "zebra bodies" in renal biopsy: Fabry disease? comparative case reports. BMC Nephrol. 2017;18:157.

44. Albay D, Adler SG, Philipose J, et al. Chloroquine-induced lipidosis mimicking Fabry disease. Mod Pathol. 2005;18:733-738.

45. Muller-Hocker J, Schmid H, Weiss M, et al. Chloroquine-induced phospholipidosis of the kidney mimicking Fabry's disease: case report and review of the literature. Hum Pathol. 2003;34:285-289.

46. Pintavorn P, Cook WJ. Progressive renal insufficiency associated with amiodarone-induced phospholipidosis. Kidney Int. 2008;74:1354-1357.

47. D'Amico DJ, Kenyon KR, Ruskin JN. Amiodarone keratopathy: druginduced lipid storage disease. Arch Ophthalmol. 1981;99:257-261.

48. Scheurle C, Dammrich M, Becker JU, et al. Renal phospholipidosis possibly induced by ranolazine. Clin Kidney J. 2014;7:62-64.

49. Filippone EJ, Carson JM, Beckford RA, et al. Sirolimus-induced pneumonitis complicated by pentamidine-induced phospholipidosis in a renal transplant recipient: a case report. Transplant Proc. 2011;43:2792-2797.

50. Munic V, Banjanac M, Kostrun S, et al. Intensity of macrolide antiinflammatory activity in J774A.1 cells positively correlates with cellular accumulation and phospholipidosis. Pharmacol Res. 2011;64:298-307.

51. Banks DE, Milutinovic J, Desnick RJ, et al. Silicon nephropathy mimicking Fabry's disease. Am J Nephrol. 1983;3:279-284.

52. Desnick RJ, Allen KY, Simmons RL, et al. Fabry disease: correction of the enzymatic deficiency by renal transplantation. Birth Defects Orig Artic Ser. 1973:9:88-96.

53. Wang AM, Desnick RJ. Structural organization and complete sequence of the human alpha- $\mathrm{N}$-acetylgalactosaminidase gene: homology with the alpha-galactosidase A gene provides evidence for evolution from a common ancestral gene. Genomics. 1991;10:133-142.

54. Wang AM, Bishop DF, Desnick RJ. Human alpha-N-acetylgalactosaminidasemolecular cloning, nucleotide sequence, and expression of a full-length cDNA. Homology with human alpha-galactosidase A suggests evolution from a common ancestral gene. J Biol Chem. 1990;265:21859-21866.

55. Ramos EL, Tisher CC. Recurrent diseases in the kidney transplant. Am J Kidney Dis. 1994;24:142-154.

56. Bollée G, Cochat P, Daudon M. Recurrence of crystalline nephropathy after kidney transplantation in APRT deficiency and primary hyperoxaluria. Can J Kidney Health Dis. 2015;2:31.

57. Rudnicki M. FSGS Recurrence in Adults after Renal Transplantation. Biomed Res Int. 2016;2016:3295618.

58. Paull LS, Lipinski MJ, Wilson WG, et al. Female with Fabry Disease Unknowingly Donates Affected Kidney to Sister: A Call for Pre-transplant Genetic Testing. JIMD reports. 2012;4:1-4.

59. Odani K, Okumi M, Honda K, et al. Kidney transplantation from a mother with unrecognized Fabry disease to her son with low a-galactosidase A activity: A 14-year follow-up without enzyme replacement therapy. Nephrology (Carlton). 2016;21(Suppl 1):57-59. 